\title{
Hepatitis C Virus in Pregnancy
}

\author{
Mona R. Prasad, DO, MPH ${ }^{1}$ Jonathan R. Honegger, MD²,3 \\ ${ }^{1}$ Division of Maternal Fetal Medicine, Department of Obstetrics and \\ Gynecology, Wexner Medical Center, The Ohio State University \\ College of Medicine, Columbus, Ohio \\ 2 Department of Pediatrics, The Ohio State University College of \\ Medicine, Columbus, Ohio \\ ${ }^{3}$ Center for Vaccine and Immunity, The Research Institute, Nationwide \\ Children's Hospital, Columbus, Ohio
}

\begin{abstract}
Address for correspondence and reprint requests Mona R. Prasad, DO, MPH, Division of Maternal Fetal Medicine, Department of Obstetrics and Gynecology, Wexner Medical Center, The Ohio State University, 395 W. 12th Avenue, Columbus, OH 43210 (e-mail: mona.prasad@osumc.edu).
\end{abstract}

\begin{abstract}
Keywords

- hepatitis C virus (HCV)

- pregnancy

- mother to child transmission

- screening

Despite recent advances in the pathogenesis, treatment, and public health response to hepatitis $\mathrm{C}$ virus (HCV), HCV as it specifically relates to pregnancy has been a neglected condition. HCV-monoinfected pregnant women have a 2-8\% risk of viral transmission to their infant, but the mechanism and timing of mother to child transmission (MTCT) are not fully understood, nor is the natural history of the illness in pregnant women and their offspring. Recognition of HCV-infected pregnant women is relevant because of the long-term health implications for the mother, potential adverse effects of infection on pregnancy outcomes, and the possibility of transmission to their infants. Certain risk factors for MTCT of HCV appear similar to those for human immunodeficiency virus (HIV); however, unlike HIV, effective methods for prevention of HCV vertical transmission have not been developed. It is possible that a better understanding of HCV MTCT and pathogenesis in pregnancy will guide development of useful prevention strategies, particularly as we enter an era where interferon-free drug cocktails may emerge as viable treatment options for HCV.
\end{abstract}

Hepatitis C virus (HCV) infection is the most common chronic blood-borne disease in the United States. Following its identification in 1989, HCV was recognized to be a major global public health problem affecting 170 million people worldwide $-3 \%$ of the population. ${ }^{1}$ In the United States, an estimated 4.1 million people (1.6\%) have been infected, of whom 2.7 million (1.3\%) have persistent viremia, the marker of chronic infection. ${ }^{2}$ Though often clinically silent initially, chronic HCV infection is important because it predisposes to eventual development of liver fibrosis and hepatocellular carcinoma, as well as numerous extrahepatic complications. ${ }^{3}$ Late-stage hepatic complications of HCV already compose the leading indication for liver transplantation and are anticipated to continue to increase in frequency in the next decade such that by 2020 , one million Americans will be living with HCVrelated cirrhosis. ${ }^{4}$ Following eradication of blood product- associated HCV infections in the 1990s, intravenous drug use is now the primary route of new HCV infections in adults, and mother-to-child transmission (MTCT) is the major route of new infections in young children in the developed world. ${ }^{5}$

More than 20 years after identification of the virus, there is still no vaccine and current interferon (IFN)-based treatment regimens are difficult and often unsuccessful. Furthermore, a recent Institute of Medicine report has contended that poor control of the HCV epidemic is compounded by inadequate public health resources and a lack of knowledge of about hepatitis $\mathrm{C}$ among at risk populations, health care providers, and policy makers. ${ }^{6}$ Nevertheless, breakthroughs in drug development have raised hopes for a new era in the HCV epidemic. The first direct-acting antivirals were approved in 2011, and a host of new drug candidates are in clinical trials. ${ }^{7}$ Numerous advances in the immunobiology of HCV have received

January 5, 2013

accepted

January 16, 2013

published online

February 6, 2013
Copyright $\odot 2013$ by Thieme Medical Publishers, Inc., 333 Seventh Avenue, New York, NY 10001, USA. Tel: +1(212) 584-4662.
DOI http://dx.doi.org/ 10.1055/s-0033-1334459. ISSN $0735-1631$. 
yielded practical tools including genetic polymorphism tests that predict likelihood of response to treatment. ${ }^{8}$ Finally, recognition of the climbing rates of $\mathrm{HCV}$ complications and possibilities of more effective treatment regimens have led to a more assertive public health approach to HCV diagnosis. Whereas recommendations for HCV testing were previously limited to patients with certain medical or behavioral risk factors for HCV infection, in 2012 the Centers for Disease Control and Prevention (CDC) added a recommendation for universal screening of all persons born between 1945 and 1965 regardless of personal risk factors because of the higher rates of $\mathrm{HCV}$ in people of this age group and their likelihood of encountering complications soon. ${ }^{9}$

These advances in HCV science, therapies, and policies for adults have not been matched in pregnant populations. Although it is known that HCV monoinfected pregnant women have a 2 to $8 \%$ risk of viral transmission to their infant, the mechanism and timing of MTCT are not well understood, nor is the natural history of the illness in pregnant women and their offspring. To date, no clear practice guidelines for pregnant women with HCV have been established. In fact, a recent review for the U.S. Preventative Services Task Force failed to identify any definitive evidencebased interventions for the prevention of MTCT. ${ }^{10} \mathrm{HCV}$, as will be reviewed, does have several parallels to human immunodeficiency virus (HIV) with regard to risk factors for MTCT. Implicit to this readership is the respect for the public health coup that has nearly eliminated MTCT of HIV via antiretroviral therapy and appropriately performed cesarean delivery. Practitioners seek similar recommendations for intervention in the setting of HCV. We may even be inclined to execute similar strategies in absence of sound evidence when caring for women with HCV in an attempt to prevent MTCT. This review intends to address the current fund of knowledge that exists regarding HCV in pregnancy and will comment on screening for HCV, adverse pregnancy outcomes associated with HCV, timing and pathogenesis of MTCT, maternal disease evolution in pregnancy, and risk factors for MTCT. We intend, also, to identify areas of future research, which may provide the evidence upon which to build appropriate practice patterns for management of HCV in pregnancy.

\section{Screening}

Current American College of Obstetricians and Gynecologists (ACOG) recommendations for HCV screening in pregnancy follow $\mathrm{CDC}$ guidelines for risk factor-based screening in the general population. ${ }^{11,12}$ In 2012, the CDC added recommendations for universal one-time screening of all U.S. "baby boomers" regardless of reported risk factors. ${ }^{9}$ This new recommendation was prompted by a recognition of the climbing rate of HCV complications in the United States, the disproportionate burden of HCV disease in this cohort, and the failure of risk factor-based screening to identify most individuals. Current CDC recommendations for HCV screening are listed in - Table $\mathbf{1}$.

In practice, the targeted approach to HCV screening in pregnancy has proven difficult, and it is likely that most $\mathrm{HCV}$ - infected pregnant women are not identified. ${ }^{13-15}$ Aside from physician reluctance to discuss risk factors and testing, 40 to $70 \%$ of HCV-infected pregnant women do not initially report major risk factors. ${ }^{16,17}$ Several of the CDC risk factors of "uncertain" significances such as a history of multiple sexual partners or sexually transmitted diseases are rather ubiquitous and of little utility for predicting maternal infection. A recent report by Delgado-Borrego et al estimated that 85 to 95\% of HCV-infected children in the United States have not been identified, ${ }^{18}$ presumably due in part to the failure to identify most maternal infections.

Given the inherent inadequacies of risk factor-based screening, several have investigated whether universal screening for $\mathrm{HCV}$ in pregnancy would be a better approach. Patients do not seem opposed to the notion of screening for $\mathrm{HCV}$. When a United Kingdom population was approached with the option of universal screening, $84 \%$ of women accepted the test and $92 \%$ felt the test should be offered to all women. ${ }^{17}$ Universal screening would additionally ensure that children born to HCV-infected women, a population for whom the CDC recommends screening, are properly identified and get appropriate postnatal evaluation. However, when Plunkett and Grobman modeled universal screening in a pregnant population with $1 \% \mathrm{HCV}$ seroprevalence, they found that it was not cost-effective, even when benefits of $\mathrm{HCV}$ diagnosis and treatment were considered for both mothers and infants and assuming that cesarean section eliminated perinatal transmission. ${ }^{19}$

An effective screening strategy utilizes an inexpensive and sensitive test to identify asymptomatic individuals at risk of a disease that has reasonably high prevalence, serious consequences if left untreated, and an effective treatment available. ${ }^{20} \mathrm{HCV}$ screening in pregnancy meets most of these criteria except, as will be reviewed, the consequences of HCV infection are often delayed for many years, there are no confirmed interventions for prevention of MTCT, and current therapies of established infection in mothers and children are expensive, associated with major side effects, and often ineffective. Without the basic tenets of effective screening upheld, the argument for universal screening folds (-Table 2). ${ }^{102}$

\section{Prevalence of Hepatitis C among Pregnant Women}

The current prevalence of HCV in pregnant women in the United States is unknown because the recommended practice of selectively screening for HCV among high-risk patients risk misses a large proportion of infected pregnant women, and no recent large scale HCV serosurvey data are available for this population. HCV seroprevalence among women of childbearing age was estimated to be $1 \%$ (age 20 to 29 years) to $1.6 \%$ (age 30 to 39 years) in 1999 to 2002 National Health and Nutrition Examination Survey (NHANES) surveys, ${ }^{2}$ though these data excluded homeless and imprisoned women who may have rates of HCV 20 to 40 times higher. ${ }^{21-23}$ Seropositivity rates in pregnant women ranged from 0.24 to $4.3 \%$ in several U.S. studies conducted between 1991 and 2003, ${ }^{24-27}$ 
Table 1 CDC and ACOG Recommendations for Screening

ACOG recommendations for HCV screening in pregnancy

- Routine prenatal HCV screening is not recommended; however, women with significant risk factors for infection should be offered antibody screening.

CDC recommendations for HCV screening in general population

HCV testing is recommended for anyone at increased risk for HCV infection, including:

- Persons born from 1945 through 1965

- Persons who have ever injected illegal drugs, including those who injected only once many years ago

- Recipients of clotting factor concentrates made before 1987

- Recipients of blood transfusions or solid organ transplants before July 1992

- Patients who have ever received long-term hemodialysis treatment

- Persons with known exposures to HCV, such as

- health care workers after needlesticks involving HCV-positive blood

o recipients of blood or organs from a donor who later tested HCV-positive

- All persons with HIV infection

- Patients with signs or symptoms of liver disease

- Children born to HCV-positive mothers

Testing of uncertain need

- Recipients of transplanted tissue (e.g., corneal, musculoskeletal, skin, ova, sperm)

- Intranasal cocaine and other noninjecting illegal drug users

- Persons with a history of tattooing or body piercing

- Persons with a history of multiple sex partners or sexually transmitted diseases

- Long-term steady sex partners of HCV-positive persons

Abbreviations: ACOG, American College of Obstetricians and Gynecologists; CDC, Centers for Disease Control and Prevention; HCV, hepatitis C virus; HIV, human immunodeficiency virus.

Source: ACOG Practice Bulletin 2007. ${ }^{11}$

Source: CDC, Recommendations for Prevention and Control of Hepatitis C Virus (HCV) Infection and HCV-Related Chronic Disease (1998) ${ }^{12}$ and Recommendations for the Identification of Chronic Hepatitis C Virus Infection Among Persons Born During 1945-1965 (2012). ${ }^{9}$

but most were single-site studies and none were designed to be nationally representative. It is conceivable that the prevalence of HCV among pregnant women might be lower today than in the 1990s because fewer transfusion-associated cases would be expected. However, reductions in transfusionassociated cases may be offset by increased numbers of cases acquired by intravenous drug use, related especially with the ongoing opiate abuse epidemic. Several recent state reports describe a doubling or tripling in the incidence of acute HCV in adolescents and young adults following the turn of the century. $^{28,29}$ Concurrently, Salihu and colleagues report climbing HCV prevalence in pregnancy. Between 1998 and 2007, the prevalence of HCV in pregnant women as determined by discharge data increased from $17 / 100,000$ births to $125.1 / 100,000$ births $(p<0.0001) .{ }^{30}$ Thus, although no recent actual seroprevalence data are available for HCV in pregnant U.S. women, recent data suggest that it is likely to be climbing.

\section{Effects of Pregnancy on the Course of Acute and Chronic HCV Infection}

Outside of pregnancy, most acute HCV infections are asymptomatic or cause mild nonspecific symptoms such as malaise and anorexia, whereas 10 to $20 \%$ lead to overt icteric hepatitis. $^{31,32}$ Symptoms (if present) and transaminase elevations usually follow a prolonged viremic incubation period that averages 7 to 8 weeks (range, 2 to 26), ${ }^{3}$ and they are likely immune-mediated as they correlate temporally with appearance of functional $\mathrm{HCV}$-specific $\mathrm{CD}^{+}$and $\mathrm{CD} 4^{+}$T-cell responses in the blood and declines in viremia (-Fig. 1; reviewed in Rehermann). ${ }^{33}$ In about 20 to $25 \%$ of acute

Table 2 Challenges of Universal Screening Versus Risk Factor-based Screening in the Pregnant Population

\begin{tabular}{|l|l|}
\hline Universal screening & Risk factor-based screening \\
\hline Not cost-effective & Difficult to ascertain risk factors \\
\hline Lack of effective therapy in pregnancy & $\begin{array}{l}40-70 \% \text { of women with HCV do not reported identifiable } \\
\text { risk factors }\end{array}$ \\
\hline No evidence-based intervention to limit MTCT of HCV & Current strategies may miss $85-95 \%$ of infected children $^{18}$ \\
\hline No protocol to link identified women to resources for care & \\
\hline
\end{tabular}

Abbreviations: $\mathrm{HCV}$, hepatitis C virus; $\mathrm{MTCT}$, mother-to-child transmission. 


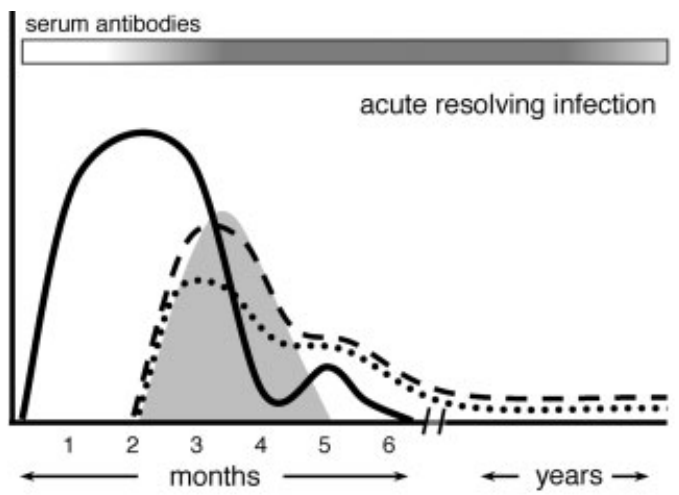

serum antibodies
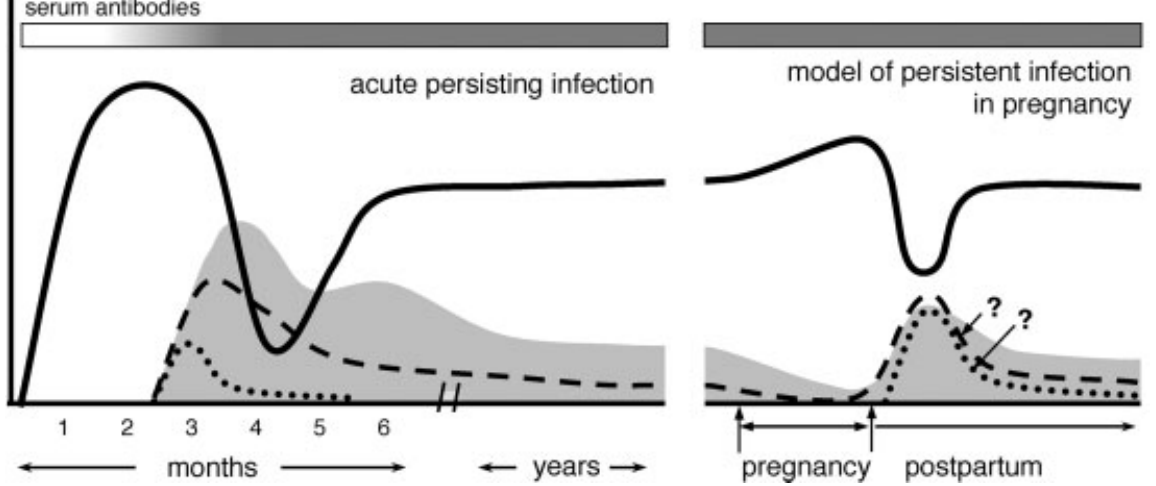

Figure 1 Patterns of viremia and cellular immunity in acute resolving infection, acute persisting infection, and a model of chronic hepatitis $C$ virus (HCV) infection during pregnancy. (Upper left) Following a prolonged incubation period, viremia declines when $\mathrm{HCV}^{-s p e c i f i c ~} \mathrm{CD} 8^{+}$and $\mathrm{CD} 4^{+} \mathrm{T}$ cells appear in the blood. Concurrent spikes in alanine aminotransferase (ALT) levels likely reflect immune-mediated hepatocyte injury. Successful T-cell responses do not fully contract into memory populations until after viremia is resolved. (Bottom left) In persisting infections viremia may be temporarily contained but eventually rebounds as $\mathrm{HCV}$-specific $\mathrm{CD} 4^{+} \mathrm{T}$-cell responses are lost and $\mathrm{CD} 8^{+} \mathrm{T}$-cell responses become ineffective. (Bottom right) In some women, viral levels rise during pregnancy and then decline significantly in the postpartum period, together with inverse changes in ALT. In this model we hypothesize that these viral load and ALT fluctuations reflect further suppression of the already dysfunctional $\mathrm{HCV}$-specific T-cell responses during pregnancy followed by a sharp and unusual rebound in T-cell function after delivery.

infections, immunity prevails and viremia spontaneously resolves ( - Fig. 1, upper panel). For the majority, however, immunity fails and lifelong infection ensues. The chronic phase of infection is characterized by exhausted cellular immunity, stable high-level viremia, and normal or elevated alanine aminotransferase (ALT; - Fig. 1, lower left panel). Affected individuals are often asymptomatic or have only nonspecific findings such as fatigue. Inability to clear viremia has been linked to an unexplained early loss of $\mathrm{HCV}$-specific $\mathrm{CD}^{+}{ }^{+} \mathrm{T}$-cell immunity and development of $\mathrm{CD} 8^{+} \mathrm{T}$ cells that are functionally exhausted or evaded by viral escape mutations. ${ }^{33}$ Innate immunity is also important for control of acute infection as genetic differences in elements controlling interleukin (IL) 28B (IFN- $\lambda$ ) and receptors governing natural killer (NK) cell activation have been linked to the outcome of infection $^{34,35}$ and numerous viral mechanisms to block innate immune signaling have been identified. ${ }^{33}$

How the immune changes of pregnancy affect the course of acute hepatitis $\mathrm{C}$ infection is not well understood as less than a dozen cases have been described (reviewed in Gonzalez et al). ${ }^{36,37}$ Interestingly, jaundice is present in the majority of reported cases of pregnant women with acute $\mathrm{HCV}$, but this may reflect a diagnostic or publication bias rather than evidence of more severe disease in pregnancy. ${ }^{36,37}$ Indeed, asymptomatic acute HCV infection in pregnancy is difficult to diagnose unless there is a distinct exposure that permits accurate timing of seroconversion. Whether pregnancy alters the outcome of acute HCV infection is unknown, but it is conceivable that the immunomodulation of pregnancy could favor viral persistence rather than clearance. ${ }^{37}$ At the same time, it is unknown if acute infection during pregnancy is more likely to result in MTCT or adverse pregnancy outcomes than chronic infection. Premature delivery was described in three of eight reported cases of $\mathrm{HCV}$, but this again could represent a bias for publication of more severe cases. ${ }^{36,37}$

Several key studies of viral levels in chronically infected pregnant women have documented a modest increase $(0.2$ to $0.8 \log \mathrm{IU} / \mathrm{mL}$ ) in average viral load over the course of pregnancy, concurrent with declines in ALT to levels that are lower than would be expected from hemodilution alone. $^{38-40}$ Because ALT elevation is thought to reflect immune-mediated hepatocyte injury rather than toxicity from viral replication per se, several authors have speculated that these viral load and ALT changes in pregnancy reflect suppression of cellular immunity by the maternofetal tolerance mechanisms of pregnancy that prevent rejection of the HLA semimismatched fetus, ${ }^{38,39}$ though no published studies have tested this hypothesis. Interestingly, some women 
sustain unusually sharp decreases in viremia 1 to 3 months after delivery, ${ }^{41}$ and a few go on to actually resolve their chronic viremia in the postpartum period, ${ }^{42}$ an otherwise rare phenomenon. ${ }^{43}$ We have observed that women with significant postpartum declines in viremia have broader HCVspecific T-cell IFN- $\gamma$-producing responses, ${ }^{44}$ suggesting these revived cells might be responsible for postpartum viral declines (-Fig. 1, lower right panel). Efforts are ongoing to better characterize this unusual postpartum restoration of HCV-specific T-cell responses and define the associated cytokine environment. These observations have led to intriguing suggestions that the immunologic milieu of the postpartum period may be a strategic time for maternal antiviral treatment. ${ }^{5,45}$

\section{Adverse Pregnancy Outcomes Associated with HCV}

Although it is clear that pregnancy affects immune control of $\mathrm{HCV}$, it has been less clear how chronic $\mathrm{HCV}$ affects pregnancy outcomes. Only recently have studies been sufficiently powered to distinguish the contribution of $\mathrm{HCV}$ to adverse pregnancy outcomes from tobacco, alcohol, drug use and other confounding variables that disproportionately affect HCV-positive women. ${ }^{46}$ Small studies conducted in the first years after discovery of the virus did not identify adverse obstetric or fetal outcomes statistically associated with HCV infection, ${ }^{24,47}$ though several noted an increased rate of cesarean delivery, ${ }^{25,47,48}$ which authors speculated could reflect inability of obstetricians to use fetal scalp electrodes for reassurance of fetal status. ${ }^{48}$ Since then, larger populationbased and case-control studies have inconsistently uncovered independent associations of maternal HCV infection with gestational diabetes, ${ }^{49,50}$ preterm delivery, ${ }^{46}$ low birth weight, ${ }^{46,49}$ small for gestational age, ${ }^{49}$ and cholestasis of pregnancy (-Table 3). ${ }^{51-53}$

The increased risk of gestational diabetes among HCVinfected pregnant women is plausible given that chronic HCV infection increases the risk of insulin resistance and diabetes mellitus in nonpregnant persons. ${ }^{54}$ Mechanisms for prematurity and low-birth-weight/small-for-gestational-age outcomes in HCV are not known-and could reflect inadequately controlled effects of maternal substance usebut one study of placental immunity in HCV infection suggested that alterations such as increased cytotoxicity of placental NK T cells could potentially account for the increased risk of preterm delivery. ${ }^{55}$

\section{Pathogenesis of MTCT of HCV}

The timing and route by which HCV passes from mother to child, and the host defense mechanisms that govern this transmission, remain poorly understood. As with HIV, estimates of the timing of transmission have relied on the presence or absence of viral RNA in the neonate at delivery, and both intrauterine and peripartum transmission events have been described. Mok et al reported that $31 \%$ of 54 HCVinfected children were HCV RNA polymerase chain reaction

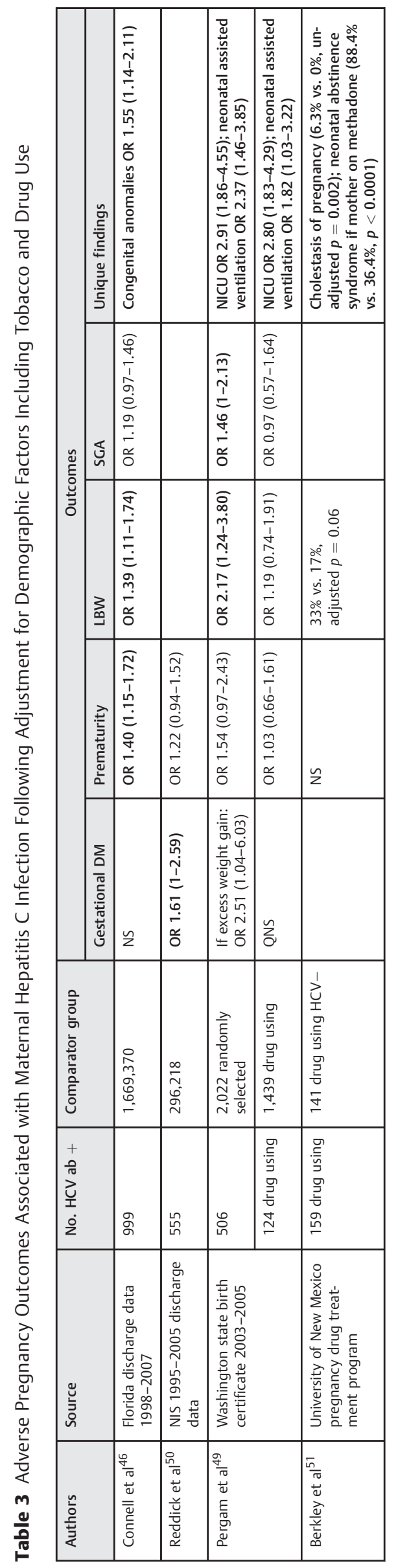


(PCR)-positive in the first 3 days after birth, consistent with intrauterine transmission. The remainder were assumed to have late intrauterine or intrapartum transmission on the basis of a negative PCR in the first 3 days of life and a subsequent positive PCR months later. ${ }^{56}$ Other studies substantiate the likelihood that both intrauterine and late intrauterine/intrapartum transmission events can occur. ${ }^{57,58}$

As recently reviewed by Le Campion et al, ${ }^{45}$ there are several routes by which HCV could conceivably cross the placenta to accomplish in utero transmission, including transcytosis, trafficking in maternal mononuclear cells, ${ }^{59,60}$ receptor mediated entry into and possibly infection of trophoblasts, ${ }^{61,62}$ or other injury to the placental barrier. With an estimated $10^{13}$ to $10^{14}$ virions circulating through the placental vascular bed daily, ${ }^{63}$ it is likely that some viral particles enter the fetal circulation even if the mechanism of transplacental passage is inefficient. In cases of intrapartum transmission, it is conceivable that transmission occurs by leakage of maternal blood into fetal circulation across the placenta during labor or via cutaneous injuries (e.g., fetal scalp electrode).

Given the probability that some viral particles enter the fetal circulation in most pregnancies, it is rather remarkable that the rate of HCV MTCT is as low as it is (2 to $8 \%$ for HCV versus $25 \%$ for HIV). This conundrum has prompted investigation into the immune mechanisms that limit HCV MTCT. Starting at the maternal-fetal interface, Hurtado and colleagues characterized innate immune cells in the decidua, placenta, and cord blood, comparing HCV-infected women to healthy controls. ${ }^{55}$ Relative to cord blood, placental tissues had greater frequencies of NK T and $\gamma \delta \mathrm{T}$ cells and greater cytotoxicities of NK T and NK cells, suggesting that an antiviral immune gradient exists at the interface. HCV infection further enhanced placental NK T and $\gamma \delta$ T-cell frequencies and placental NK T cytotoxicity while at the same time reducing expression of NK-cell activation markers in both compartments. Given the role of NK cells in immunity to acute HCV infection in adults, these findings suggest that placental immune cells may play an active antiviral role in limiting MTCT of HCV. ${ }^{55}$

Hypothesizing that some viral particles enter the fetal circulation in most pregnancies, Babik and colleagues examined fetal cellular adaptive immunity and plasma inflammatory markers using cord blood of seven neonates born to HCVpositive women, compared with eight neonates born to HCVnegative women. ${ }^{63}$ Although no $\mathrm{HCV}$-specific T-cell responses were detected in the exposed neonates, relative to controls these exposed neonates had suppression of T-cell activation markers and plasma proinflammatory markers that was counterbalanced by increased capacity of $\mathrm{T}$ cells to produce IFN- $\gamma$ upon polyclonal stimulation. ${ }^{63}$ These distinct changes in the fetal immune system were interpreted as evidence that the fetal immune system had come into contact with HCV. Several studies have examined HCV-specific T-cell responses in older aviremic children born to HCV-infected women. ${ }^{64,65} \mathrm{HCV}$-specific T cells were detected in some of the children, but it is not yet clear whether these responses were primed following in utero or later household exposure, ${ }^{66}$ nor is it clear whether they contributed to immune protection or were simply markers of past exposure. Genetic studies of HLA types have identified several candidate class II alleles associated with protection from or predisposition to vertical transmission, supporting a role of fetal antigen-specific $\mathrm{CD} 4^{+} \mathrm{T}$-cell immunity in governing MTCT, but most candidate class II alleles have not been corroborated in subsequent studies. ${ }^{67-69}$

Infection, or at least association, of HCV with maternal peripheral blood mononuclear cells (PBMCs) has been linked to an increased risk of MTCT in studies by Azzari, Indolfi, Resti, and colleagues. ${ }^{59,60,70}$ The authors reasoned that if maternal PBMCs are a conduit for HCV MTCT, then fetal alloimmune responses that target maternal cells may be protective against transmission, and mother-child pairs with high concordance of HLA alleles (the primary molecules targeted by fetal alloimmune responses against leukocytes) should be at higher risk of MTCT. Concordance of class I molecules was not shown to be associated with increased risk of transmission, ${ }^{71}$ but in support of their theory concordance of class II HLA molecules did in fact significantly increase the risk of vertical transmission. ${ }^{67}$

Additional genetic factors known to be determinants of infection outcome in adults have been examined for a role in the risk of HCV MTCT, including polymorphisms in IL28B promotor, ${ }^{34,72}$ mannose binding lectin, tumor necrosis factor- $\alpha$, IFN- $\gamma$, IL-10, and transforming growth factor- $\beta^{67}$ None of these were associated with altered risk of HCV MTCT, though IL28B genotype was predictive of viral clearance in the infant once transmission had occurred. ${ }^{72}$ Finally, fetal gender has been identified as a possible risk factor for MTCT, as a European collaborative study identified that females were twice as likely as males to be affected by MTCT (adjusted odds ratio [OR], 2.07; $95 \%$ confidence interval $[\mathrm{CI}], 1.23$ to $3.48 ; p=0.006) .{ }^{73}$

\section{Clinical Risk Factors for MTCT}

Clinical risk factors for MTCT echo those seen in HIV: demonstrable viral load, exposure to maternal blood, prolonged rupture of membranes, and internal fetal monitoring. Maternal coinfection with HIV also increases this risk (-Table 4). ${ }^{86,88,94,95,103-108}$

\section{Viral Load}

Much data exist regarding the risk that maternal viremia poses to MTCT. It is generally accepted that transmission does not occur in the setting of undetectable viral loads, $26,58,74,75$ as there are only a few cases of such transmission in the literature potentially explained by lack of sensitivity of RNA testing to detect lower levels of viremia or transient viremia. ${ }^{76-78}$ Mast and colleagues submit that further studies of MTCT be limited to those who are RNA-positive or at least stratified by RNA status. $^{26}$

There appears to be an increased risk of MTCT with increasing levels of viremia. Steininger and colleagues demonstrated that viral loads were higher among transmitters than nontransmitters in women undergoing vaginal delivery $\left(8.1 \times 10^{5}\right.$ versus $\left.1.4 \times 10^{4}, p=0.056\right),{ }^{58}$, and Mast et al had 
Table 4 Clinical Risk Factors for MTCT

\begin{tabular}{|c|c|}
\hline Maternal risk factor & Risk of MTCT \\
\hline HCV PCR-positive ${ }^{103-105}$ & $3-40 \%$ \\
\hline HCV PCR-negative ${ }^{56}$ & $0 \%$ \\
\hline Breastfeeding $58,94,95$ & $0-3.7 \%$ \\
\hline HIV-positive $^{58,86,106,107}$ & $15-26 \%$ \\
\hline HIV-negative $^{57,86,88,108}$ & $0-12 \%$ \\
\hline IV drug abuse and transfusion ${ }^{104}$ & $7-12 \%$ \\
\hline IV drug abuse ${ }^{95}$ & $8.6 \%$ \\
\hline Ruptured membranes $>6$ h, PCR-positive ${ }^{26}$ & 8.6\%, OR 9.3 (95\% Cl 1.5-179.7) \\
\hline Internal fetal monitoring, PCR-positive ${ }^{26}$ & 18.8\%, OR 6.7 (95\% Cl 1.1-35.9) \\
\hline
\end{tabular}

Abbreviations: $\mathrm{Cl}$, confidence interval; HCV, hepatitis C virus; HIV, human immunodeficiency virus; IV, intravenous; MTCT, mother-to-child transmission; OR, odds ratio; PCR, polymerase chain reaction.

similar findings in HCV monoinfected mothers. ${ }^{26}$ Dal Molin et al found that women with markedly elevated levels above $10^{7}$ $\mathrm{IU} / \mathrm{mL}$ appeared to be at particularly high risk of transmission (OR 10.2, $p=0.03$ ). ${ }^{75}$ Nevertheless, no lower threshold of viremia below which transmission does not occur has been determined. As a matter of practicality, viral RNA testing may be most useful in counseling patients who demonstrate absence of viremia.

\section{Exposure to Maternal Blood}

Steininger et al determined that children delivered vaginally to mothers who sustained a vaginal or perineal laceration had sixfold higher risks of becoming HCV-infected. ${ }^{58}$ Exposure to maternal blood can be extrapolated in the setting of twins affected discordantly. Boxall et al reported on four sets of twins where MTCT was discordant, and in three of the four sets, the second twin was the one infected. There were no episiotomies or internal monitors used in any case. They postulated that placental separation allows inoculation of the second twin, but it may be additionally considered that exposure to maternal blood after the delivery of the first twin is increased with the delivery of the second. ${ }^{79}$

\section{Prolonged Rupture of Membranes and Internal Fetal Monitoring}

The obstetric factors of prolonged monitoring and internal fetal monitoring (scalp electrodes and intrauterine pressure catheter, IUPC) have been shown to increase risk of MTCT. In cases where membrane rupture occurs $>6$ hours before delivery, higher rates of MTCT have been demonstrated. ${ }^{80,81}$ Mast and colleagues conducted a multivariate analysis restricted to HCV RNA-positive mothers and determined membrane rupture $>6$ hours to be significantly associated with MTCT (OR, 9.3; 95\% CI, 1.5 to 179.7). Their data additionally identify use of internal fetal monitors to be similarly associated (OR, 6.7; 95\% CI, 1.1 to 35.9). ${ }^{26}$

\section{Amniocentesis}

Though Minola et al acknowledged that amniocentesis may contribute to the risk of MTCT, ${ }^{82}$ a prospective study followed
22 HCV-positive women and compared them with 11 controls. All women underwent amniocentesis in the fourth month of pregnancy. Of the 22 women, 16 demonstrated viremia, and in only one of the viremic women $(6.3 \%)$ was $\mathrm{HCV}$ virus detected. This did not result in $\mathrm{HCV}$ infection in the offspring. ${ }^{83}$ Additionally, as the single case of identification of HCV in the amniotic fluid occurred in the presence of anterior placentation, the possibility of contamination from transplacental passage does exist. The data on amniocentesis are limited in pregnancy, but is not thought to significantly increase the risk of MTCT.

\section{Maternal Disease Severity}

In a study among HCV RNA-positive mothers, elevated prepregnancy ALT levels were associated with an increased risk of vertical transmission, though quantitative viral load measurements were not available to distinguish if hepatocyte injury was an independent predictor of MTCT. ${ }^{84}$

\section{HIV Coinfection}

Maternal HIV coinfection has been consistently associated with an increased risk of HCV MTCT upon meta-analysis (OR 2.8; $95 \% \mathrm{CI}, 1.17$ to 6.81$).{ }^{85}$ Reasons for this increased risk are unclear, but could relate to higher levels of HCV in maternal plasma or PBMC compartments, ${ }^{86,87}$ altered immunity at the placental barrier, or physical disruption of the placenta due to HIV infection of trophoblasts (reviewed in Le Campion et al)..$^{45}$ To our knowledge, no studies have addressed whether suppression of HIV in the highly active antiretroviral therapy era ameliorates this increased risk of HCV transmission in coinfected women.

\section{Cesarean Delivery}

Those interested in HCV MTCT see the inherent similarities to HIV with regard to obstetric risk factors for transmission of a blood-borne virus. Therefore, it is not difficult to extrapolate that interventions such as cesarean delivery might effectively eliminate peripartum transmission. Much interest was piqued when Gibb and colleagues published their work in 2000, examining the impact of mode of delivery on MTCT ${ }^{57}$ In their 
study, 441 mother-infant pairs from the United Kingdom and Ireland were included. Overall vertical transmission rate was 6.7\%, 3.8 times higher in HIV-positive women. Transmission rates were $7.7 \%$ among 339 women undergoing vaginal delivery, 5.9\% among 54 women undergoing emergency cesarean section, and 0\% among 31 women undergoing elective cesarean section. ${ }^{57}$ Though Paccagnini et al suggested similar promise in their cohort, ${ }^{88}$ the benefit of elective cesarean has yet to be confirmed. Many studies have found no association between mode of delivery and decreased MTCT rates. ${ }^{73,89,90}$ One analysis found that elective cesarean section would need to substantially reduce the risk of perinatal transmission to be cost-effective (e.g., a 77\% reduction in transmission would be required if the background perinatal transmission rate were 7.7\%). ${ }^{91}$ Current evidence does not support the use of elective cesarean section to prevent MTCT. The Cochrane Database solidifies the recommendations, stating, "Currently there is no evidence from randomised controlled trials upon which to base any practice recommendations regarding planned caesarean section versus vaginal delivery for preventing mother to infant HCV transmission." 92

\section{Breastfeeding}

Until recently the risk associated with breastfeeding in the setting of maternal infection with HCV has been controversial. Although HCV is demonstrated in the human milk and colostrum, ${ }^{93,94}$ the quantity is too low to infect the newborn. Other theories imply that gastric secretions may inactivate the virus. ${ }^{57,80,94-96}$ Both the American Academy of Pediatrics and ACOG endorse safe breastfeeding as defined by absence of cracked, damaged, or bleeding nipples. In the setting of HIV coinfection, recommendations remain to avoid breastfeeding. ${ }^{97}$

\section{Treatment of HCV during Pregnancy}

Combined pegylated IFN- $\alpha$ and ribavirin for 24 to 48 weeks have been standard therapy for HCV. However, this regimen results in a sustained virological response (undetectable viral load through 6 months after completing treatment) in only approximately $50 \%$ of persons infected with the most prevalent genotype, and it is associated with a host of constitutional, psychiatric, hematologic, and other side effects. ${ }^{98}$ Treatment in pregnancy is not an option because of safety concerns. Ribavirin in particular is contraindicated (Food and Drug Administration [FDA] pregnancy category $\mathrm{X}$ ) because of teratogenic effects in numerous animal studies at low doses. ${ }^{99}$ Ribavirin has a long half-life, and avoidance is recommended for women and their male partners starting 6 months prior to conception. ${ }^{99}$ Nevertheless, preliminary data from a ribavirin birth registry have not corroborated teratogenic effects in humans. ${ }^{99}$ Pegylated IFN- $\alpha$ is FDA pregnancy category $C$, and experience is limited in pregnancy, though a recent review of IFN- $\alpha$ exposed pregnancies did not identify adverse fetal outcomes. ${ }^{100}$ Therapy in the postpartum period has not been widely utilized because it is contraindicated in breastfeeding, and even for the nonbreastfeeding mother, therapy is not likely practical while caring for a young infant given the significant side effects of this regimen. Nevertheless, breakthroughs in $\mathrm{HCV}$ drug development have raised hope for a new era of HCV therapy. A flurry of new drug candidates termed direct-acting antivirals have been identified, including compounds that target the HCV NS3/4A protease, the NS5B polymerase, the NS5A protein, as well as host proteins critical for HCV replication. ${ }^{7}$ In 2011, two protease inhibitors, telaprevir and boceprevir, were FDA-approved for genotype 1 infection. Addition of these drugs increased sustained virological response rates for treatment naïve genotype 1 infections from $38-44 \%$ with standard therapy to $66-74 \% .{ }^{101}$ Viral resistance mutations emerge readily to these protease inhibitors, necessitating their use as adjuncts to standard pegylated IFN- $\alpha$ and ribavirin therapy, but the hope is that new multidrug cocktails in development will replace IFN.

Improved efficacy and tolerability of new drug regimens may open possibilities for treatment of HCV in pregnancy or the postpartum period. Antiviral treatment during pregnancy such as done for HIV may help prevent HCV MTCT, but it is not clear that this will be justified given that pediatric HCV may also be more readily curable with new drug regimens and pediatric HCV lacks the early consequences of pediatric HIV. ${ }^{5}$ Antiviral treatment in the postpartum period, however, may prove to be a strategic approach for multiple reasons, including possible improved efficacy from a synergistic effect with rebounding immunity in this time frame, ${ }^{5,44,45}$ recent engagement of the HCV-infected mother in the health care system, and the potential to prevent future pregnancies complicated by maternal HCV. Furthermore, improved efficacy of new drug regimens will require reassessment of the utility of universal screening for HCV in pregnant women. The cost-effectiveness analysis of universal HCV screening in pregnancy by Plunkett and Grobman ${ }^{19}$ assumed treatment efficacy of 54\% (range 50 to 58\%), whereas it is conceivable that new regimens will have efficacy $>90 \%$. Finally, as public health goals shift toward more aggressive screening of HCV in the general population to reduce HCV morbidity ${ }^{9}$ and eventually eliminate adult and pediatric $\mathrm{HCV}$, universal $\mathrm{HCV}$ screening in pregnancy may prove to be a logical step.

\section{Concluding Remarks}

$\mathrm{HCV}$ as it relates to pregnancy is poorly understood, large numbers of HCV-infected pregnant women are never identified, and practice patterns for optimal management of pregnancies affected by HCV have not been established. Obstetric risk factors for MTCT of HCV share some similarities with HIV MTCT. However, unlike HIV, effective interventions for prevention of HCV MTCT have not been confirmed. It is possible that a better understanding of the pathogenesis and clinical risk factors for HCV MTCT will lead to useful prevention strategies. Furthermore, better insight into the unique changes in HCV-specific immunity during and after pregnancy may inform new treatment approaches, particularly as new IFNfree drug therapies for HCV emerge. If effective MTCT prevention strategies are identified or pharmacotherapies are found appropriate in these settings, arguments against comprehensive HCV screening in pregnancy may be nullified. 
The Eunice Kennedy Shriver National Institute of Child Health and Human Development Maternal-Fetal Medicine Units Network has prioritized a multicenter observational cohort study to further define risk factors for MTCT and adverse pregnancy outcomes associated with HCV in a prospective trial. It is hoped that this large clinical trial will not only address Institute of Medicine priorities outlined earlier, but in conjunction with the basic science efforts described in this article, also help establish optimal practice patterns for women and their children affected by HCV.

\section{Acknowledgements}

We thank Dr. Christopher Walker for his helpful comments on this review and acknowledge support from the National Institutes of Health (R01-AI096882).

\section{References}

1 Shepard CW, Finelli L, Alter MJ. Global epidemiology of hepatitis C virus infection. Lancet Infect Dis 2005;5:558-567

2 Armstrong GL, Wasley A, Simard EP, McQuillan GM, Kuhnert WL, Alter MJ. The prevalence of hepatitis $C$ virus infection in the United States, 1999 through 2002. Ann Intern Med 2006;144: 705-714

3 Lauer GM, Walker BD. Hepatitis C virus infection. N Engl J Med 2001;345:41-52

4 Davis GL, Alter MJ, El-Serag H, Poynard T, Jennings LW. Aging of hepatitis $\mathrm{C}$ virus (HCV)-infected persons in the United States: a multiple cohort model of HCV prevalence and disease progression. Gastroenterology 2010;138:513-521, e1-e6

5 Arshad M, El-Kamary SS, Jhaveri R. Hepatitis C virus infection during pregnancy and the newborn period-are they opportunities for treatment? J Viral Hepat 2011;18:229-236

6 Mitchell AE, Colvin HM, Palmer Beasley R. Institute of Medicine recommendations for the prevention and control of hepatitis $B$ and C. Hepatology 2010;51:729-733

7 Poordad F, Dieterich D. Treating hepatitis C: current standard of care and emerging direct-acting antiviral agents. J Viral Hepat 2012;19:449-464

8 Ge D, Fellay J, Thompson AJ, et al. Genetic variation in IL28B predicts hepatitis $C$ treatment-induced viral clearance. Nature 2009;461:399-401

9 Smith BD, Morgan RL, Beckett GA, et al; Centers for Disease Control and Prevention. Recommendations for the identification of chronic hepatitis $C$ virus infection among persons born during 1945-1965. MMWR Recomm Rep 2012;61:1-32

10 Cottrell EB, Chou R, Wasson N, Rahman B, Guise JM. Reducing risk for mother-to-infant transmission of hepatitis $C$ virus: a systemic review for the U.S. Preventative Services Task Force. Ann Int Med 2013;158:109-113

11 Practice Bulletin No ACOG; American College of Obstetricians and Gynecologists. 86: Viral hepatitis in pregnancy. Obstet Gynecol 2007;110:941-956

12 Alter MJ, Margolis HS, Bell BP, et al; Centers for Disease Control and Prevention. Recommendations for prevention and control of hepatitis $\mathrm{C}$ virus (HCV) infection and HCV-related chronic disease. MMWR Recomm Rep 1998;47:1-39

13 Giles M, Hellard M, Sasadeusz J. Hepatitis C and pregnancy: an update. Aust N Z J Obstet Gynaecol 2003;43:290-293

14 Blasig A, Wagner EC, Pi D, et al; BC HCV Vertical Transmission Study Group. Hepatitis $C$ infection among pregnant women in British Columbia: reported prevalence and critical appraisal of current prenatal screening methods. Can J Public Health 2011;102:98-102
15 Pinto CS, Martins RM, Andrade SM, Stief AC, Oliveira RD, Castro AR. Hepatitis $C$ virus infection among pregnant women in Central-Western Brazil, 2005-2007. Rev Saude Publica 2011;45:974-976

16 Conte D, Fraquelli M, Prati D, Colucci A, Minola E. Prevalence and clinical course of chronic hepatitis $\mathrm{C}$ virus (HCV) infection and rate of $\mathrm{HCV}$ vertical transmission in a cohort of 15,250 pregnant women. Hepatology 2000;31:751-755

17 Ward C, Tudor-Williams G, Cotzias T, Hargreaves S, Regan L, Foster GR. Prevalence of hepatitis $C$ among pregnant women attending an inner London obstetric department: uptake and acceptability of named antenatal testing. Gut 2000;47:277-280

18 Delgado-Borrego A, Smith L, Jonas MM, et al. Expected and actual case ascertainment and treatment rates for children infected with hepatitis C in Florida and the United States: epidemiologic evidence from statewide and nationwide surveys. J Pediatr 2012;161:915-921

19 Plunkett BA, Grobman WA. Routine hepatitis C virus screening in pregnancy: a cost-effectiveness analysis. Am J Obstet Gynecol 2005;192:1153-1161

20 Wilson JM, Jungner YG. Principles and practices of screening for disease. Bol Oficina Sanit Panam 1968;65:281-393

21 Nyamathi AM, Dixon EL, Robbins W, et al. Risk factors for hepatitis $\mathrm{C}$ virus infection among homeless adults. J Gen Intern Med 2002;17:134-143

22 Fox RK, Currie SL, Evans J, et al. Hepatitis C virus infection among prisoners in the California state correctional system. Clin Infect Dis 2005;41:177-186

23 Macalino GE, Dhawan D, Rich JD. A missed opportunity: hepatitis C screening of prisoners. Am J Public Health 2005;95: 1739-1740

24 Bohman VR, Stettler RW, Little BB, Wendel GD, Sutor LJ, Cunningham FG. Seroprevalence and risk factors for hepatitis $C$ virus antibody in pregnant women. Obstet Gynecol 1992;80: 609-613

25 Silverman NS, Jenkin BK, Wu C, McGillen P, Knee G. Hepatitis C virus in pregnancy: seroprevalence and risk factors for infection. Am J Obstet Gynecol 1993;169:583-587

26 Mast EE, Hwang LY, Seto DS, et al. Risk factors for perinatal transmission of hepatitis $\mathrm{C}$ virus (HCV) and the natural history of HCV infection acquired in infancy. J Infect Dis 2005;192: 1880-1889

27 Bradley JS, Graham S, Picchio GR, Vugia DJ, Kharrazi M. Prevalence of hepatitis $C$ virus antibody in newborn infants in southern California in 2003. Pediatr Infect Dis J 2011;30:618-620

28 Centers for Disease Control and Prevention (CDC). Notes from the field: risk factors for hepatitis $C$ virus infections among young adults-Massachusetts, 2010. MMWR Morb Mortal Wkly Rep 2011;60:1457-1458

29 Centers for Disease Control and Prevention (CDC). Notes from the field: hepatitis C virus infections among young adults-rural Wisconsin, 2010. MMWR Morb Mortal Wkly Rep 2012;61:358

30 Salihu HM, Connell L, Salemi JL, August EM, Weldeselasse HE, Alio AP. Prevalence and temporal trends of hepatitis B, hepatitis C, and HIV/AIDS co-infection during pregnancy across the decade, 1998-2007. J Womens Health (Larchmt) 2012;21:66-72

31 Alter MJ, Margolis HS, Krawczynski K, et al. The natural history of community-acquired hepatitis $C$ in the United States. The Sentinel Counties Chronic non-A, non-B Hepatitis Study Team. N Engl J Med 1992;327:1899-1905

32 Hoofnagle JH. Course and outcome of hepatitis C. Hepatology 2002;36(5, Suppl 1):S21-S29

33 Rehermann B. Hepatitis C virus versus innate and adaptive immune responses: a tale of coevolution and coexistence. J Clin Invest 2009;119:1745-1754

34 Thomas DL, Thio CL, Martin MP, et al. Genetic variation in IL28B and spontaneous clearance of hepatitis C virus. Nature 2009; 461:798-801 
35 Khakoo SI, Thio CL, Martin MP, et al. HLA and NK cell inhibitory receptor genes in resolving hepatitis $C$ virus infection. Science 2004;305:872-874

36 Kogure T, Ueno Y, Kanno N, et al. Sustained viral response of a case of acute hepatitis $C$ virus infection via needle-stick injury. World J Gastroenterol 2006;12:4757-4760

37 Gonzalez F, Medam-Djomo MA, Lucidarme D, et al. Acute hepatitis $\mathrm{C}$ during the third trimester of pregnancy. Gastroenterol Clin Biol 2006;30:786-789

38 Wejstål R, Widell A, Norkrans G. HCV-RNA levels increase during pregnancy in women with chronic hepatitis C. Scand J Infect Dis 1998;30:111-113

39 Gervais A, Bacq Y, Bernuau J, et al. Decrease in serum ALT and increase in serum HCV RNA during pregnancy in women with chronic hepatitis C. J Hepatol 2000;32:293-299

40 Paternoster DM, Santarossa C, Grella P, et al. Viral load in HCV RNA-positive pregnant women. Am J Gastroenterol 2001; 96:2751-2754

$41 \mathrm{Lin} \mathrm{HH}$, Kao JH. Hepatitis C virus load during pregnancy and puerperium. BJOG 2000;107:1503-1506

42 Hattori Y, Orito E, Ohno T, et al. Loss of hepatitis C virus RNA after parturition in female patients with chronic HCV infection. J Med Virol 2003;71:205-211

43 Watanabe H, Saito T, Shinzawa H, et al. Spontaneous elimination of serum hepatitis C virus (HCV) RNA in chronic HCV carriers: a population-based cohort study. J Med Virol 2003;71:56-61

44 Honegger J, Prasad M, Walker C. Broadened virus-specific T-cell responses are associated with postpartum declines in hepatitis $C$ viremia, Abstract 1225. In: Infectious Diseases Society of America Annual Meeting. San Diego, CA: 2012

45 Le Campion A, Larouche A, Fauteux-Daniel S, Soudeyns H. Pathogenesis of hepatitis $C$ during pregnancy and childhood. Viruses 2012;4:3531-3550

46 Connell LE, Salihu HM, Salemi JL, August EM, Weldeselasse H, Mbah AK. Maternal hepatitis B and hepatitis C carrier status and perinatal outcomes. Liver Int 2011;31:1163-1170

47 Floreani A, Paternoster D, Zappala F, et al. Hepatitis C virus infection in pregnancy. Br J Obstet Gynaecol 1996;103:325-329

48 Hillemanns P, Dannecker C, Kimmig R, Hasbargen U. Obstetric risks and vertical transmission of hepatitis $C$ virus infection in pregnancy. Acta Obstet Gynecol Scand 2000;79:543-547

49 Pergam SA, Wang CC, Gardella CM, Sandison TG, Phipps WT, Hawes SE. Pregnancy complications associated with hepatitis C: data from a 2003-2005 Washington state birth cohort. Am J Obstet Gynecol 2008;199:e1-e9

50 Reddick KL, Jhaveri R, Gandhi M, James AH, Swamy GK. Pregnancy outcomes associated with viral hepatitis. J Viral Hepat 2011;18: e394-e398

51 Berkley EM, Leslie KK, Arora S, Qualls C, Dunkelberg JC. Chronic hepatitis C in pregnancy. Obstet Gynecol 2008;112(2 Pt 1):304-310

52 Locatelli A, Roncaglia N, Arreghini A, Bellini P, Vergani P, Ghidini A. Hepatitis $C$ virus infection is associated with a higher incidence of cholestasis of pregnancy. Br J Obstet Gynaecol 1999;106:498-500

53 Paternoster DM, Fabris F, Palù G, et al. Intra-hepatic cholestasis of pregnancy in hepatitis C virus infection. Acta Obstet Gynecol Scand 2002;81:99-103

54 White DL, Ratziu V, El-Serag HB. Hepatitis C infection and risk of diabetes: a systematic review and meta-analysis. J Hepatol 2008;49:831-844

55 Hurtado CW, Golden-Mason L, Brocato M, Krull M, Narkewicz MR, Rosen HR. Innate immune function in placenta and cord blood of hepatitis C-seropositive mother-infant dyads. PLoS ONE 2010;5: e12232

56 Mok J, Pembrey L, Tovo PA, Newell ML; European Paediatric Hepatitis C Virus Network. When does mother to child transmission of hepatitis C virus occur? Arch Dis Child Fetal Neonatal Ed 2005;90:F156-F160
57 Gibb DM, Goodall RL, Dunn DT, et al. Mother-to-child transmission of hepatitis $C$ virus: evidence for preventable peripartum transmission. Lancet 2000;356:904-907

58 Steininger C, Kundi M, Jatzko G, Kiss H, Lischka A, Holzmann H. Increased risk of mother-to-infant transmission of hepatitis $C$ virus by intrapartum infantile exposure to maternal blood. J Infect Dis 2003;187:345-351

59 Azzari C, Moriondo M, Indolfi G, et al. Higher risk of hepatitis C virus perinatal transmission from drug user mothers is mediated by peripheral blood mononuclear cell infection. J Med Virol 2008;80:65-71

60 Azzari C, Resti M, Moriondo M, Ferrari R, Lionetti P, Vierucci A. Vertical transmission of HCV is related to maternal peripheral blood mononuclear cell infection. Blood 2000;96:2045-2048

61 Nie QH, Gao LH, Cheng YQ et al. Hepatitis C virus infection of human cytotrophoblasts cultured in vitro. J Med Virol 2012; 84:1586-1592

62 Mostafavi A, Arshad M, Qiang G, Bradrick S, Jhaveri R. Examining cells of trophoblastic origin for permissiveness for hepatitis $C$ virus replication. Abstract 1338. In: Infectious Diseases Society of America Annual Meeting. San Diego, CA:2012

63 Babik JM, Cohan D, Monto A, Hartigan-O'Connor DJ, McCune JM. The human fetal immune response to hepatitis $C$ virus exposure in utero. J Infect Dis 2011;203:196-206

64 El-Kamary SS, Hashem M, Saleh DA, et al. Hepatitis C virusspecific cell-mediated immune responses in children born to mothers infected with hepatitis C virus. J Pediatr 2013;162: 148-154

65 Della Bella S, Riva A, Tanzi E, et al. Hepatitis C virus-specific reactivity of $\mathrm{CD} 4$ + -lymphocytes in children born from HCVinfected women. J Hepatol 2005;43:394-402

66 Hashem M, El-Karaksy H, Shata MT, et al. Strong hepatitis C virus (HCV)-specific cell-mediated immune responses in the absence of viremia or antibodies among uninfected siblings of HCV chronically infected children. J Infect Dis 2011;203:854-861

67 Bevilacqua E, Fabris A, Floreano P, et al; EPHN collaborators. Genetic factors in mother-to-child transmission of HCV infection. Virology 2009;390:64-70

68 Bosi I, Ancora G, Mantovani W, et al. HLA DR13 and HCV vertical infection. Pediatr Res 2002;51:746-749

69 Martinetti M, Pacati I, Cuccia M, et al. Hierarchy of baby-linked immunogenetic risk factors in the vertical transmission of hepatitis C virus. Int J Immunopathol Pharmacol 2006;19:369-378

70 Indolfi G, Resti M. Perinatal transmission of hepatitis C virus infection. J Med Virol 2009;81:836-843

71 Azzari C, Indolfi G, Betti L, et al. Vertical hepatitis C virus transmission is not related to mother-child class-1 HLA concordance. Int J Immunopathol Pharmacol 2007;20:827-831

72 Ruiz-Extremera A, Muñoz-Gámez JA, Salmerón-Ruiz MA, et al. Genetic variation in interleukin 28B with respect to vertical transmission of hepatitis $C$ virus and spontaneous clearance in HCV-infected children. Hepatology 2011;53:1830-1838

73 European Paediatric Hepatitis C Virus Network. A significant sex -but not elective cesarean section-effect on mother-to-child transmission of hepatitis $\mathrm{C}$ virus infection. J Infect Dis 2005;192:1872-1879

74 Giacchino R, Tasso L, Timitilli A, et al. Vertical transmission of hepatitis $C$ virus infection: usefulness of viremia detection in HIV-seronegative hepatitis C virus-seropositive mothers. J Pediatr 1998;132:167-169

75 Dal Molin G, D'Agaro P, Ansaldi F, et al. Mother-to-infant transmission of hepatitis $C$ virus: rate of infection and assessment of viral load and IgM anti-HCV as risk factors. J Med Virol 2002;67:137-142

76 Granovsky MO, Minkoff HL, Tess BH, et al. Hepatitis C virus infection in the mothers and infants cohort study. Pediatrics 1998;102(2 Pt 1):355-359 
77 Resti M, Azzari C, Galli L, et al; Italian Study Group on Mother-toInfant Hepatitis C Virus Transmission. Maternal drug use is a preeminent risk factor for mother-to-child hepatitis $\mathrm{C}$ virus transmission: results from a multicenter study of 1372 motherinfant pairs. J Infect Dis 2002;185:567-572

78 Dore GJ, Kaldor JM, McCaughan GW. Systematic review of role of polymerase chain reaction in defining infectiousness among people infected with hepatitis C virus. BMJ 1997; 315:333-337

79 Boxall E, Baumann K, Price N, Sira J, Brown M, Kelly D. Discordant outcome of perinatal transmission of hepatitis $\mathrm{C}$ in twin pregnancies. J Clin Virol 2007;38:91-95

80 Spencer JD, Latt N, Beeby PJ, et al. Transmission of hepatitis C virus to infants of human immunodeficiency virus-negative intravenous drug-using mothers: rate of infection and assessment of risk factors for transmission. J Viral Hepat 1997;4:395-409

81 Thomas SL, Newell ML, Peckham CS, Ades AE, Hall AJ. A review of hepatitis $C$ virus (HCV) vertical transmission: risks of transmission to infants born to mothers with and without HCV viraemia or human immunodeficiency virus infection. Int $\mathrm{J}$ Epidemiol 1998;27:108-117

82 Minola E, Maccabruni A, Pacati I, Martinetti M. Amniocentesis as a possible risk factor for mother-to-infant transmission of hepatitis C virus. Hepatology 2001;33:1341-1342

83 Delamare C, Carbonne B, Heim N, et al. Detection of hepatitis C virus RNA (HCV RNA) in amniotic fluid: a prospective study. J Hepatol 1999;31:416-420

84 Indolfi G, Azzari C, Moriondo M, Lippi F, de Martino M, Resti M. Alanine transaminase levels in the year before pregnancy predict the risk of hepatitis C virus vertical transmission. J Med Virol 2006;78:911-914

85 Polis CB, Shah SN, Johnson KE, Gupta A. Impact of maternal HIV coinfection on the vertical transmission of hepatitis $C$ virus: a meta-analysis. Clin Infect Dis 2007;44:1123-1131

86 Zanetti AR, Tanzi E, Paccagnini S, et al; Lombardy Study Group on Vertical HCV Transmission. Mother-to-infant transmission of hepatitis C virus. Lancet 1995;345:289-291

87 Blackard JT, Smeaton L, Hiasa Y, et al. Detection of hepatitis C virus (HCV) in serum and peripheral-blood mononuclear cells from HCV-monoinfected and HIV/HCV-coinfected persons. J Infect Dis 2005;192:258-265

88 Paccagnini S, Principi N, Massironi E, et al. Perinatal transmission and manifestation of hepatitis $C$ virus infection in a high risk population. Pediatr Infect Dis J 1995;14:195-199

89 Airoldi J, Berghella V. Hepatitis C and pregnancy. Obstet Gynecol Surv 2006;61:666-672

90 Roberts EA, Yeung L. Maternal-infant transmission of hepatitis C virus infection. Hepatology 2002;36(5, Suppl 1):S106-S113

91 Plunkett BA, Grobman WA. Elective cesarean delivery to prevent perinatal transmission of hepatitis $C$ virus: a cost-effectiveness analysis. Am J Obstet Gynecol 2004;191:998-1003

92 McIntyre PG, Tosh K, McGuire W. Caesarean section versus vaginal delivery for preventing mother to infant hepatitis $C$ virus transmission. Cochrane Database Syst Rev 2006;(4):CD005546
93 Kumar RM, Shahul S. Role of breast-feeding in transmission of hepatitis C virus to infants of HCV-infected mothers. J Hepatol 1998;29:191-197

94 Lin HH, Kao JH, Hsu HY, et al. Absence of infection in breast-fed infants born to hepatitis C virus-infected mothers. J Pediatr 1995;126:589-591

95 Yeung LT, King SM, Roberts EA. Mother-to-infant transmission of hepatitis C virus. Hepatology 2001;34:223-229

96 European Paediatric Hepatitis C Virus Network. Effects of mode of delivery and infant feeding on the risk of mother-to-child transmission of hepatitis C virus. BJOG 2001;108:371-377

97 American College of Obstetricians and Gynecologists. ACOG Practice Bulletin No. 86: Viral hepatitis in pregnancy. Obstet Gynecol 2007;110:941-956

98 Ghany MG, Strader DB, Thomas DL, Seeff LB; American Association for the Study of Liver Diseases . Diagnosis, management, and treatment of hepatitis C: an update. Hepatology 2009;49:1335-1374

99 Roberts SS, Miller RK, Jones JK, et al. The Ribavirin Pregnancy Registry: Findings after 5 years of enrollment, 2003-2009. Birth Defects Res A Clin Mol Teratol 2010;88:551-559

100 Yazdani Brojeni P, Matok I, Garcia Bournissen F, Koren G. A systematic review of the fetal safety of interferon alpha. Reprod Toxicol 2012;33:265-268

101 Ghany MG, Nelson DR, Strader DB, Thomas DL, Seeff LB; American Association for Study of Liver Diseases. An update on treatment of genotype 1 chronic hepatitis C virus infection: 2011 practice guideline by the American Association for the Study of Liver Diseases. Hepatology 2011;54:1433-1444

102 Io M. Hepatitis and liver cancer: a national strategy for prevention and control of hepatitis B and C. In: Colvin HM, Mitchell AE, eds. Committee on the Prevention and Control of Viral Hepatitis Infections; Institute of Medicine. Washington, DC: The National Academic Press; 2010

103 La Torre A, Biadaioli R, Capobianco T, et al. Vertical transmission of HCV. Acta Obstet Gynecol Scand 1998;77:889-892

104 Resti M, Azzari C, Mannelli F, et al; Tuscany Study Group on Hepatitis C Virus Infection. Mother to child transmission of hepatitis $C$ virus: prospective study of risk factors and timing of infection in children born to women seronegative for HIV-1. BMJ 1998;317:437-441

105 Ohto H, Terazawa S, Sasaki N, et al; The Vertical Transmission of Hepatitis C Virus Collaborative Study Group. Transmission of hepatitis C virus from mothers to infants. N Engl J Med 1994;330:744-750

106 Tovo PA, Palomba E, Ferraris G, et al; Italian Study Group for HCV Infection in Children. Increased risk of maternal-infant hepatitis $C$ virus transmission for women coinfected with human immunodeficiency virus type 1 . Clin Infect Dis 1997;25:1121-1124

107 Ferrero S, Lungaro P, Bruzzone BM, Gotta C, Bentivoglio G, Ragni N. Prospective study of mother-to-infant transmission of hepatitis C virus: a 10-year survey (1990-2000). Acta Obstet Gynecol Scand 2003;82:229-234

108 Fischler B, Lindh G, Lindgren S, et al. Vertical transmission of hepatitis C virus infection. Scand J Infect Dis 1996;28:353-356 